\title{
Performance Analysis of Biscuit Manufacturing Plant in Steady State Using Fuzzy Availability \\ Pawan Kumar Chhoker
}

Departments of Mathematics, N.C. College of Engineering,

Israna Panipat, India

chhoker.pawan@rediffmail.com

\section{ABSTRACT}

This paper deals with the performance analysis of biscuit manufacturing plant consisting of six sub-systems using fuzzy availability in the steady state. These six sub-systems are arranged in series and parallel configurations. Mathematical formulation of the problem is carried out using Markov process and the governing differential equations are solved in steady state using normalizing condition. The effect of variations of fuzzy availability for different failure, repair rates and system coverage factor for each sub-system in steady state is also studied.

\section{KEYWORDS}

Manufacturing System, Modeling, Markov Process and Fuzzy Availability.

\section{Council for Innovative Research}

Peer Review Research Publishing System

Journal: International Journal of Computers \& Technology

Vol 11, No.4

editor@cirworld.com

www.cirworld.com, member.cirworld.com 


\section{MATERIAL AND METHODS}

The profust reliability theory is based on the following two assumptions:

1. Probability assumption: the system failure behavior is fully characterized in the context of probability measures.

2. Fuzzy states assumption: the system success and failure are characterized by fuzzy states. At any time the system can be viewed as being in one of the two fuzzy states to some extent. This means that system failure cannot be defined in a precise way, but in a fuzzy way.

For ease of reference, in the following we provide some essential concepts and results in profust reliability theory. For more details, refer to Cai (1996).

Suppose a system with $\mathrm{n}$ topological (non-fuzzy) states $S_{1}, S_{2}, \ldots \ldots \ldots, S_{n}$.

Let $\mathrm{U}=\left\{S_{1}, S_{2}, \ldots \ldots \ldots \ldots, S_{n}\right\}$ denote the universe of discourse. On this universe we define a fuzzy success state

$$
\tilde{S}=\left\{\left(S_{i}, \mu_{\tilde{S}}\left(S_{i}\right)\right), i=1,2, \ldots \ldots n\right\}
$$

and a fuzzy failure state

$$
\tilde{F}=\left\{\left(S_{i}, \mu_{\tilde{F}}\left(S_{i}\right)\right), i=1,2, \ldots \ldots n\right\}
$$

where $\mu_{\tilde{S}}\left(S_{i}\right)$ and $\mu_{\tilde{F}}\left(S_{i}\right)$ are the corresponding membership functions, respectively.

The system profust availability is defined as

$$
\begin{aligned}
& \tilde{A}(t)=\text { Prob }\{\text { at time } t \text { the system is in fuzzy success state } S\} . \\
& \tilde{A}(t)=\sum \mu_{\tilde{s}}\left(S_{i}\right) \cdot P_{i}(t) \quad(\text { for all success states })
\end{aligned}
$$

\section{INTRODUCTION}

The reliability engineering is one of the important engineering tasks in designing and development of a technical system. Conventional reliability theory considers the assumptions of the probability theory and the binary states of a component/system as working or failed. It is well known that the binary state modeling for reliability of components as well as for the system is too simplistic and does not capture the reality for most systems which can have many levels of performance. Let us take an example of a system comprises two independent processing units which can perform their own tasks in parallel. Evidently we can take the system to be fully functioning when both processing units are functioning and take the system to be fully failed when both processing units are failed. However, when one processing unit is functioning and the other one is failed, the system operates at degraded and demonstrates a significant attribute of performance degradation. At this point the system is neither fully functioning nor fully failed, but in intermediate state. This implies that the crisp definitions for system failure and success are no longer appropriate and thus the binary state assumption should be relaxed. Zadeh (1965) introduced fuzzy set theory. This theory can handle all the possible states between a fully working state and completely failed state. Thus the binary state assumption in conventional reliability is replaced by fuzzy state assumption. This approach to the reliability is known as profust reliability and developed by Cai (1996).An important problem in the profust reliability theory is how to plan maintenance policy in the presence of the fuzzy state assumption. Cai et al. (1991) described fuzzy reliability modeling of gracefully degradable computing systems and show that the fuzziness, coverage factor and maintenance have significant effects on the fuzzy reliability behavior of gracefully degradable computing systems. Cai et al. (1990) used fuzzy reliability for street-lighting lamps replacement and make a comparison between two replacement policies, viz. the block replacement policy in a non-fuzzy environment and the periodic replacement policy without repair at lamp failures in a fuzzy environment. Cai et al. (1991A) applied fuzzy reliability to discuss the survivability index for computer communication networks (CCNs) and also evaluated fuzzy availability to discuss the effect of maintenance. Cai et al. (1993 and 1995) used fuzzy states as a basis for a theory of fuzzy reliability and discuss all the forms of fuzzy reliability and typical systems including the series system, parallel system, markov model and mixture model. Verma et al. (2007) also discussed all the forms of fuzzy reliability. They evaluated fuzzy availability using two different approaches and fuzzy availability modeling of semi-markovian system. Verma et al. (2007) also found profust reliability of degraded diesel engine power plant and studied the effect of various parameters such as failure rates and system coverage factor on profust reliability. Chongshan (2009) calculated fuzzy availability of a repairable consecutive-2-out-of-3: F-system. Zuang (1995) presented a method of reliability analysis in the presence of fuzziness attached to operating time. Chowdhury and Misra (1992) presented a method to find an expression of fuzzy system reliability of a non-series parallel network taking into consideration the special requirements of fuzzy sets. Pandey and Tyagi (2007) calculated profust reliability of a power loom plant which is modeled as a two units gracefully 
degradable system. This paper proposed a method of failure rate parameter estimation using fuzzy numbers. Guan and Wu (2006) studied a repairable consecutive-k-out-of-n: F system with fuzzy states. Qiang et al. (2009) established an improved method of fuzzy reliability analysis on deep sliding plane in rock foundation under dam. Mohanta et al. (2005) presented a fuzzy markov model for determination of fuzzy state probabilities of generating units including the effect of maintenance scheduling. Chen (1996) presented a new method for fuzzy system reliability analysis based on fuzzy time series and the $\alpha$-cuts arithmetic operations of fuzzy number, where the reliability of the components of a system at different time can have different membership functions. Aliev and Kara (2004) used time dependent fuzzy set for fuzzy system reliability analysis. Kumar et al. (2009) calculated fuzzy reliability and fuzzy availability of the serial process in butter-oil processing plant.

\section{MATHEMATICAL MODELING OF THE SYSTEM}

Mathematical modeling is carried out using simple probabilistic considerations and differential equations associated with the transition diagram (Figure1) are developed on the basis of Markov birth-death process. These equations are further solved for determining the steady state fuzzy availability of the biscuit manufacturing plant. Various probability considerations give the following differential equations associated with the biscuit manufacturing plant.

$$
\begin{aligned}
& \frac{d P_{1}(t)}{d t}+\left(\sum_{i=1,3,6} \lambda_{i} c+\sum_{i=2,4,5} \lambda_{i}(1-c)\right) P_{1}(t)=\mu_{6} P_{2}(t)+\mu_{1} P_{3}(t)+\mu_{3} P_{5}(t) \\
& +\mu_{2} P_{9}(t)+\mu_{4} P_{10}(t)+\mu_{5} P_{11}(t) \\
& \frac{d P_{2}(t)}{d t}+\left(\mu_{6}+\sum_{i=1,6} \lambda_{i} c+\sum_{i=2,4,5,9} \lambda_{i}(1-c)\right) P_{2}(t)=\lambda_{6} c P_{1}(t)+\mu_{3} P_{6}(t)+\mu_{2} P_{12}(t)+ \\
& \mu_{4} P_{13}(t)+\mu_{5} P_{14}(t)+\mu_{9} P_{15}(t)+\mu_{1} P_{17}(t) \\
& \frac{d P_{3}(t)}{d t}+\left(\mu_{1}+\sum_{i=3,6} \lambda_{i} c+\sum_{i=2,4,5,7} \lambda_{i}(1-c)\right) P_{3}(t)=\lambda_{1} c P_{1}(t)+\mu_{3} P_{4}(t)+\mu_{6} P_{7}(t)+\mu_{7} P_{16}(t) \\
& +\mu_{2} P_{17}(t)+\mu_{4} P_{18}(t)+\mu_{5} P_{19}(t) \\
& \frac{d P_{4}(t)}{d t}+\left(\mu_{1}+\mu_{3}+\lambda_{6} c+\sum_{i=2,4,5,7,8} \lambda_{i}(1-c)\right) P_{4}(t)=\lambda_{3} c P_{3}(t)+\mu_{6} P_{8}(t)+\lambda_{1} c P_{5}(t)+ \\
& \mu_{7} P_{20}(t)+\mu_{2} P_{21}(t)+\mu_{8} P_{22}(t)+\mu_{4} P_{23}(t)+\mu_{5} P_{24}(t) \\
& \frac{d P_{5}(t)}{d t}+\left(\mu_{3}+\sum_{i=1,6} \lambda_{i} c+\sum_{i=2,4,5,8} \lambda_{i}(1-c)\right) P_{5}(t)=\lambda_{3} c P_{1}(t)+\mu_{1} P_{4}(t)+\mu_{6} P_{6}(t) \\
& +\mu_{2} P_{41}(t)+\mu_{8} P_{42}(t)+\mu_{4} P_{43}(t)+\mu_{5} P_{44}(t) \\
& \frac{d P_{6}(t)}{d t}+\left(\mu_{3}+\mu_{6}+\lambda_{1} c+\sum_{i=2,4,5,8,9} \lambda_{i}(1-c)\right) P_{6}(t)=\lambda_{3} c P_{2}(t)+\mu_{1} P_{8}(t)+\lambda_{6} c P_{5}(t)+ \\
& \mu_{2} P_{25}(t)+\mu_{8} P_{26}(t)+\mu_{4} P_{27}(t)+\mu_{5} P_{28}(t)+\mu_{9} P_{29}(t)
\end{aligned}
$$

$$
\begin{array}{r}
\frac{d P_{7}(t)}{d t}+\left(\mu_{1}+\mu_{6}+\lambda_{3} c+\sum_{i=2,4,5,7,9} \lambda_{i}(1-c)\right) P_{7}(t)=\lambda_{1} c P_{2}(t)+\mu_{3} P_{8}(t)+\lambda_{6} c P_{3}(t)+ \\
\mu_{7} P_{30}(t)+\mu_{2} P_{31}(t)+\mu_{4} P_{32}(t)+\mu_{5} P_{33}(t)+\mu_{9} P_{34}(t)
\end{array}
$$

$$
\begin{aligned}
\frac{d P_{8}(t)}{d t}+\left(\mu_{1}+\mu_{3}+\mu_{6}+\right. & \left.\sum_{\substack{i=2,4,5,7,8,9\\
}} \lambda_{i}(1-c)\right) P_{8}(t)=\lambda_{1} c P_{6}(t)+\lambda_{3} c P_{7}(t)+\mu_{7} P_{35}(t)+ \\
& \lambda_{6} c P_{4}(t)+\mu_{8} P_{37}(t)+\mu_{2} P_{36}(t)+\mu_{4} P_{38}(t)+\mu_{5} P_{39}(t)+\mu_{9} P_{40}(t)
\end{aligned}
$$

$\frac{d P_{i}(t)}{d t}+\mu_{j} P_{i}(t)=\lambda_{j}(1-c) P_{1}(t) \quad i=9,10,11$ and $j=2,4$ and 5 respectively. 
$\frac{d P_{i}(t)}{d t}+\mu_{j} P_{i}(t)=\lambda_{j}(1-c) P_{2}(t) \quad i=12,13,14,15$ and $j=2,4,5$ and 9 respectively.

(13)

$\frac{d P_{i}(t)}{d t}+\mu_{j} P_{i}(t)=\lambda_{j}(1-c) P_{3}(t) \quad i=16,17,18,19$ and $j=7,2,4$ and 5 respectively. (14)

$\frac{d P_{i}(t)}{d t}+\mu_{j} P_{i}(t)=\lambda_{j}(1-c) P_{4}(t) \quad i=20,21,22,23,24$ and $j=7,2,8,4$ and 5 respectively.

$\frac{d P_{i}(t)}{d t}+\mu_{j} P_{i}(t)=\lambda_{j}(1-c) P_{6}(t) \quad i=25,26,27,28,29$ and $j=2,8,4,5$ and 9 respectively.

(16)

$\frac{d P_{i}(t)}{d t}+\mu_{j} P_{i}(t)=\lambda_{j}(1-c) P_{7}(t) \quad i=30,31,32,33,34$ and $j=7,2,4,5$ and 9 respectively.

$\frac{d P_{i}(t)}{d t}+\mu_{j} P_{i}(t)=\lambda_{j}(1-c) P_{8}(t) \quad i=35,36,37,38,39,40$ and $j=7,2,8,4,5$ and 9 respectively.

(18)

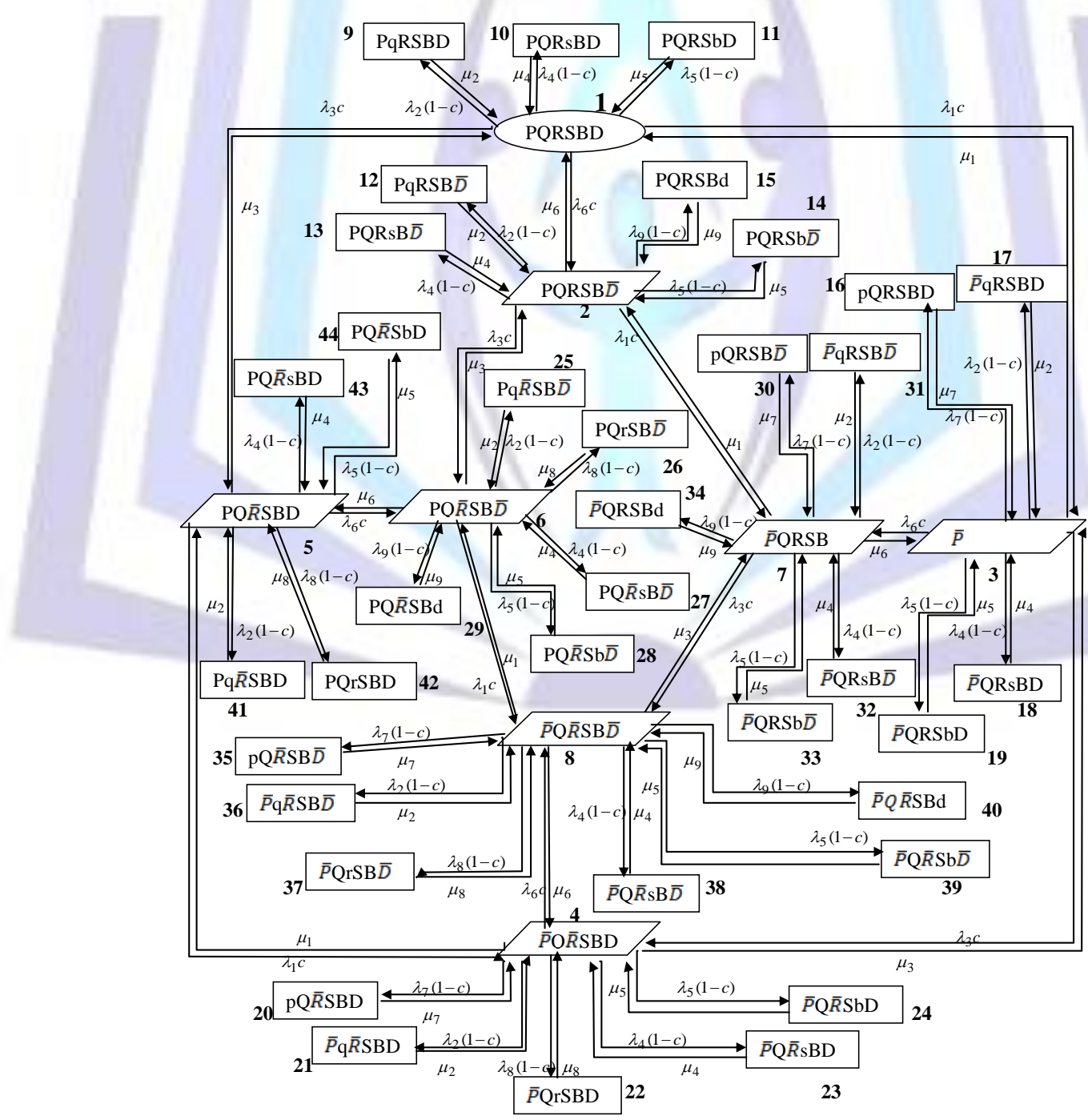

Figure 1: Transition Diagram of Biscuit Manufacturing Plant 
$\frac{d P_{i}(t)}{d t}+\mu_{j} P_{i}(t)=\lambda_{j}(1-c) P_{5}(t) \quad i=41,42,43,44$ and $j=2,8,4$ and 5 respectively.

With initial conditions

$$
P_{k}(0)= \begin{cases}1, & \text { if } k=1 \\ 0, & \text { if } k \neq 1\end{cases}
$$

Generally the management is interested in fuzzy availability of the system, which is obtained by the condition $\frac{d}{d t} \rightarrow 0$ as $t \rightarrow \infty \quad$ i.e., by putting $\frac{d}{d t}=\mathrm{O}$ and taking probabilities independent of $\mathrm{t}$ in equations from (4) to (19) we get

$$
\begin{aligned}
& \left(\sum_{i=1,3,6} \lambda_{i} c+\sum_{i=2,4,5} \lambda_{i}(1-c)\right) P_{1}=\mu_{6} P_{2}+\mu_{1} P_{3}+\mu_{3} P_{5}+\mu_{2} P_{9}+\mu_{4} P_{10}+\mu_{5} P_{11} \\
& \left(\mu_{6}+\sum_{i=1,6} \lambda_{i} c+\sum_{i=2,4,5,9} \lambda_{i}(1-c)\right) P_{2}=\lambda_{6} c P_{1}+\mu_{3} P_{6}+\mu_{2} P_{12}+\mu_{4} P_{13}+\mu_{5} P_{14}+\mu_{9} P_{15}+\mu_{1} P_{17} \\
& \left(\mu_{1}+\sum_{i=3,6} \lambda_{i} c+\sum_{i=2,4,5,7} \lambda_{i}(1-c)\right) P_{3}=\lambda_{1} c P_{1}+\mu_{3} P_{4}+\mu_{6} P_{7}+\mu_{7} P_{16}+\mu_{2} P_{17}+\mu_{4} P_{18}+\mu_{5} P_{19} \\
& \left(\begin{array}{c}
\mu_{1}+\mu_{3}+\lambda_{6} c+\sum_{i=2,4,5,7,8} \lambda_{i}(1-c) \\
y_{4}
\end{array}\right) P_{3} c P_{3}+\mu_{6} P_{8}+\lambda_{1} c P_{5}+\mu_{7} P_{20}+\mu_{2} P_{21}+\mu_{8} P_{22}+\mu_{4} P_{23}+\mu_{5} P_{24} \\
& \left(\begin{array}{c}
\mu_{3}+\sum_{i=1,6} \lambda_{i} c+\sum_{i=2,4,5,8} \lambda_{i}(1-c)
\end{array}\right) P_{5}=\lambda_{3} c P_{1}+\mu_{1} P_{4}+\mu_{6} P_{6}+\mu_{2} P_{41}+\mu_{8} P_{42}+\mu_{4} P_{43}+\mu_{5} P_{44}
\end{aligned}
$$

$$
\left(\mu_{3}+\mu_{6}+\lambda_{1} c+\sum_{i=2,4,5,8,9} \lambda_{i}(1-c)\right) P_{6}=\lambda_{3} c P_{2}+\mu_{1} P_{8}+\lambda_{6} c P_{5}+\mu_{2} P_{25}+\mu_{8} P_{26}+\mu_{4} P_{27}+\mu_{5} P_{28}+\mu_{9} P_{29}
$$

$\left(\mu_{1}+\mu_{6}+\lambda_{3} c+\sum_{i=2,4,5,7,9} \lambda_{i}(1-c)\right) P_{7}=\lambda_{1} c P_{2}+\mu_{3} P_{8}+\lambda_{6} c P_{3}+\mu_{7} P_{30}+\mu_{2} P_{31}+\mu_{4} P_{32}+\mu_{5} P_{33}+\mu_{9} P_{34}$

$$
\begin{aligned}
& \left(\mu_{1}+\mu_{3}+\mu_{6}+\sum_{i=2,4,5,7,8,9} \lambda_{i}(1-c)\right) P_{8}=\lambda_{1} c P_{6}+\lambda_{3} c P_{7}+\mu_{7} P_{35}+\lambda_{6} c P_{4}+\mu_{8} P_{37} \\
& +\mu_{2} P_{36}+\mu_{4} P_{38}+\mu_{5} P_{39}+\mu_{9} P_{40} \\
& \mu_{j} P_{i}=\lambda_{j}(1-c) P_{1} \quad i=9,10,11 \text { and } \quad j=2,4 \text { and } 5 \text { respectively. } \\
& \mu_{j} P_{i}=\lambda_{j}(1-c) P_{2} \quad i=12,13,14,15 \text { and } \quad j=2,4,5 \text { and } 9 \text { respectively. }
\end{aligned}
$$


$\mu_{j} P_{i}=\lambda_{j}(1-c) P_{3} \quad i=16,17,18,19$ and $\quad j=7,2,4$ and 5 respectively.

$\mu_{j} P_{i}=\lambda_{j}(1-c) P_{4} \quad i=20,21,22,23,24$ and $\quad j=7,2,8,4$ and 5 respectively.

$\mu_{j} P_{i}=\lambda_{j}(1-c) P_{6} \quad i=25,26,27,28,29$ and $\quad j=2,8,4,5$ and 9 respectively.

$\mu_{j} P_{i}=\lambda_{j}(1-c) P_{7} \quad i=30,31,32,33,34$ and $\quad j=7,2,4,5$ and 9 respectively.

$\mu_{j} P_{i}=\lambda_{j}(1-c) P_{8} \quad i=35,36,37,38,39,40$ and $\quad j=7,2,8,4,5$ and 9 respectively.

$\mu_{j} P_{i}=\lambda_{j}(1-c) P_{5} \quad i=41,42,43,44$ and $\quad j=2,8,4$ and 5 respectively.

Solving these equations recursively, we get

$P_{2}=K_{1} P_{1}$

(38)

(37) $P_{3}=K_{2} P_{1}$

$P_{4}=K_{3} P_{1}$

$P_{5}=K_{4} P_{1}$

(40)

$P_{6}=K_{5} P_{1}$

$P_{7}=K_{6} P_{1}$

$P_{8}=K_{7} P_{1}$

$P_{i}=\delta_{j} P_{1} \quad i=9,10,11$ and $\quad j=2,4$ and 5 respectively.

$P_{i}=\delta_{j} P_{2} \quad i=12,13,14,15$ and $\quad j=2,4,5$ and 9 respectively.

$P_{i}=\delta_{j} P_{3} \quad i=16,17,18,19$ and $\quad j=7,2,4$ and 5 respectively.

$P_{i}=\delta_{j} P_{4} \quad i=20,21,22,23,24$ and $j=7,2,8,4$ and 5 respectively.

$P_{i}=\delta_{j} P_{6} \quad i=25,26,27,28,29$ and $\quad j=2,8,4,5$ and 9 respectively.

$P_{i}=\delta_{j} P_{7} \quad i=30,31,32,33,34$ and $\quad j=7,2,4,5$ and 9 respectively.

$P_{i}=\delta_{j} P_{8} \quad i=35,36,37,38,39,40$ and $\quad j=7,2,8,4,5$ and 9 respectively.

$P_{i}=\delta_{j} P_{5} \quad i=41,42,43,44$ and $j=2,8,4$ and 5 respectively.

Where

$$
\begin{array}{ll}
K_{1}=\frac{Q_{8} T_{5}+Q_{9} T_{6}}{T_{5} T_{8}}, & K_{2}=\frac{T_{6}+T_{2} K_{1}}{T_{5}} \\
K_{3}=\frac{N_{1}+N_{2} K_{1}+Q_{3} K_{2}}{T_{4}}, & K_{4}=\frac{\lambda_{3} c+Z_{5} K_{1}+Z_{6} K_{2}+Z_{7} K_{3}}{N_{5}} \\
K_{5}=\frac{K_{1} Z_{1}+K_{2} Z_{3}+K_{3} Z_{4}+\lambda_{6} c K_{4}}{Q_{6}}, & K_{6}=\frac{\lambda_{1} c K_{1}+\lambda_{6} c K_{2}+L_{9} K_{3}+M_{2} K_{5}}{N_{7}}
\end{array}
$$




$$
\begin{aligned}
& K_{7}=\frac{\lambda_{1} c K_{5}+\lambda_{6} c K_{3}+\lambda_{3} c K_{6}}{L_{8}}, \quad T_{1}=\frac{1}{Q_{6}}\left[\frac{\lambda_{6} c L_{1}}{\mu_{3}}+\frac{Z_{4} N_{1}}{T_{4}}\right] \\
& T_{2}=\frac{1}{Q_{6}}\left[Z_{2}-\frac{\mu_{6}}{\mu_{3}}+\frac{Z_{4} N_{2}}{T_{4}}\right], \quad T_{3}=\frac{1}{Q_{6}}\left[Z_{3}-\frac{\mu_{1}}{\mu_{3}}+\frac{Z_{4} Q_{3}}{T_{4}}\right] \\
& T_{4}=\frac{1}{Q_{6}}\left[Q_{4} Q_{6}-Z_{4} Z_{10}\right], \quad T_{5}=\frac{N_{3} T_{4}-Z_{1} Q_{3}-M_{3} T_{3} T_{4}}{T_{4}} \\
& T_{6}=\frac{\lambda_{1} c T_{4}+Z_{1} N_{1}+M_{3} T_{1} T_{4}}{T_{4}} \quad T_{7}=\frac{L_{11} T_{4}+Z_{1} N_{2}+M_{3} T_{2} T_{4}}{T_{4}} \\
& T_{8}=\frac{1}{T_{5}}\left[Q_{7} T_{5}-Q_{9} T_{7}\right], \quad Q_{6}=\frac{1}{N_{7}}\left[N_{6} N_{7}-L_{14} M_{2}\right] \\
& Q_{4}=\frac{1}{N_{7}}\left[N_{4} N_{7}-L_{13} L_{9}\right], \quad Q_{3}=Z_{9}-\frac{\lambda_{1} \mu_{1} c}{\mu_{3}}+\frac{Z_{10}}{Q_{6}}\left(Z_{3}-\frac{\mu_{1}}{\mu_{3}}\right) \\
& Q_{7}=L_{2}-\frac{\mu_{3} Z_{2}}{Q_{6}}-\frac{\mu_{3} \lambda_{6} c Z_{5}}{N_{5} Q_{6}}-\frac{N_{2}}{T_{4}}\left[\frac{\mu_{3} Z_{4}}{Q_{6}}+\frac{\lambda_{6} \mu_{3} c Z_{7}}{N_{5} Q_{6}}\right] \\
& Q_{8}=\lambda_{6} c+\frac{\lambda_{6} \mu_{3} \lambda_{3} c^{2}}{N_{5} Q_{6}}+\frac{N_{1}}{T_{4}}\left[\frac{\mu_{3} Z_{4}}{Q_{6}}+\frac{\mu_{3} \lambda_{6} c Z_{7}}{N_{5} Q_{6}}\right] \\
& Q_{9}=\mu_{1} \delta_{3}+\frac{\mu_{3} Z_{3}}{Q_{6}}+\frac{\lambda_{6} \mu_{3} c Z_{6}}{N_{5} Q_{6}}+\frac{Q_{3}}{T_{4}}\left[\frac{\mu_{3} Z_{4}}{Q_{6}}+\frac{\mu_{3} \lambda_{6} c Z_{7}}{N_{5} Q_{6}}\right] \\
& L_{1}=\sum_{i=1,3,6} \lambda_{i} c, \quad L_{2}=\mu_{6}+\sum_{i=1,6} \lambda_{i} c, \quad L_{3}=\mu_{1}+\sum_{i=3,6} \lambda_{i} c \\
& L_{4}=\mu_{1}+\mu_{3}+\lambda_{6} c, \quad L_{5}=\mu_{3}+\sum_{i=1,6} \lambda_{i} c, \quad L_{6}=\mu_{3}+\mu_{6}+\lambda_{1} c \\
& L_{7}=\mu_{1}+\mu_{6}+\lambda_{3} c, \quad L_{8}=\mu_{1}+\mu_{3}+\mu_{6}, \quad L_{9}=\frac{\mu_{3} \lambda_{6} c}{L_{8}} \\
& L_{10}=\frac{\mu_{1} \lambda_{6} c}{L_{8}}, \quad L_{11}=\frac{\mu_{6} \lambda_{1} c}{N_{7}}, \quad L_{12}=\frac{\mu_{6} \lambda_{1} c}{L_{8}} \\
& L_{13}=\frac{\mu_{6} \lambda_{3} c}{L_{8}}, \quad L_{14}=\frac{\mu_{1} \lambda_{3} c}{L_{8}}, \quad M_{1}=\mu_{5} \delta_{5}+\mu_{9} \delta_{9} \\
& M_{2}=M_{1}+\frac{\mu_{3} \lambda_{1} c}{L_{8}} \quad M_{3}=\frac{\mu_{6} M_{2}}{N_{7}} \quad N_{1}=\frac{\lambda_{1} \mu_{3} c L_{1}+\lambda_{6} c Z_{10} L_{1}}{Q_{6} \mu_{3}} \\
& N_{2}=Z_{8}-\frac{\lambda_{1} \mu_{6} c}{\mu_{3}}+\frac{Z_{10}}{Q_{6}}\left[Z_{2}-\frac{\mu_{6}}{\mu_{3}}\right], \quad N_{3}=L_{3}-\frac{\lambda_{6} \mu_{6} c}{N_{7}} \\
& N_{4}=L_{4}-\frac{\lambda_{6} \mu_{6} c}{L_{8}}, \quad N_{5}=L_{5}-\frac{\lambda_{6} \mu_{6} c}{Q_{6}}, \quad N_{6}=L_{6}-\frac{\lambda_{1} \mu_{1} c}{L_{8}}
\end{aligned}
$$




$$
\begin{array}{ccc}
N_{7}=L_{7}-\frac{\lambda_{3} \mu_{3} c}{L_{8}}, & Z_{1}=\mu_{3}+\frac{\mu_{6} L_{9}}{N_{7}}, & Z_{2}=\lambda_{3} c+\frac{L_{14} \lambda_{1} c}{N_{7}} \\
Z_{3}=\frac{\lambda_{6} c L_{14}}{N_{7}}, & Z_{4}=L_{10}+\frac{L_{14} L_{9}}{N_{7}}, & Z_{5}=\frac{\mu_{6} Z_{2}}{Q_{6}} \\
Z_{6}=\frac{\mu_{6} Z_{3}}{Q_{6}}, & Z_{7}=\mu_{1}+\frac{\mu_{6} Z_{4}}{Q_{6}}, & Z_{8}=\frac{\lambda_{1} c L_{13}}{N_{7}} \\
Z_{9}=\lambda_{3} c+\frac{L_{13} \lambda_{6} c}{N_{7}}, & Z_{10}=L_{12}+\frac{L_{13} M_{2}}{N_{7}}, & \delta_{i}=\frac{\lambda_{i}(1-c)}{\mu_{i}} \quad i=1,2, \ldots \ldots .9
\end{array}
$$

Now, using the normalizing condition $\sum_{i=1}^{44} P_{i}=1$, we get

$$
P_{1}=\left[\begin{array}{l}
\left(1+\sum_{i=1,4,5} \delta_{i}\right)+K_{1}\left(1+\sum_{i=2,4,5,9} \delta_{i}\right)+K_{2}\left(1+\sum_{i=2,4,5,7} \delta_{i}\right)+K_{3}\left(1+\sum_{i=2,4,5,7,8} \delta_{i}\right)+ \\
K_{4}\left(1+\sum_{i=2,4,5,8} \delta_{i}\right)+K_{5}\left(1+\sum_{i=2,4,5,8,9} \delta_{i}\right)+K_{6}\left(1+\sum_{i=2,4,5,7,9} \delta_{i}\right)+K_{7}\left(1+\sum_{i=2,4,5,7,8,9} \delta_{i}\right)
\end{array}\right]^{-1}
$$

The fuzzy availability $\widetilde{A}(\infty)$ of the system

$$
\begin{aligned}
\tilde{A}(\infty) & =P_{1}+\frac{3}{4} P_{2}+\frac{3}{4} P_{3}+\frac{1}{2} P_{4}+\frac{3}{4} P_{5}+\frac{1}{2} P_{6}+\frac{1}{2} P_{7}+\frac{1}{4} P_{8} \\
= & {\left[1+\frac{3}{4} K_{1}+\frac{3}{4} K_{2}+\frac{1}{2} K_{3}+\frac{3}{4} K_{4}+\frac{1}{2} K_{5}+\frac{1}{2} K_{6}+\frac{1}{4} K_{7}\right] P_{1} }
\end{aligned}
$$

\section{RESULTS AND DISCUSSION}

We now consider the effect of various parameters on fuzzy availability of the system in this section. Here, the fuzzy availability of the system is computed by altering the failure and repair rates of the sub-systems.

\section{(i) Effect of failure rates and repair rates of Mixing on fuzzy availability of the}

system: - The effect of failure and repair rates on fuzzy availability of the system is studied by varying the values of $\lambda_{1} \& \mu_{1}$. The failure and repair rates of other sub-systems have been taken as: $\lambda_{2}=0.0002, \lambda_{3}=0.004, \lambda_{4}=0.015, \lambda_{5}$ $=0.0052, \quad \lambda_{6}=0.0002, \lambda_{7}=0.0001, \lambda_{8}=0.008, \quad \lambda_{9}=0.0047, \mu_{2}=0.02, \mu_{3}=0.46, \mu_{4}=0.1, \mu_{5}=0.08, \mu_{6}=0.06, \mu_{7}=0.002$, $\mu_{8}=0.31, \mu_{9}=0.9$. The fuzzy availability of the system is calculated using this data and the results are shown in Table 1 (given in appendix-A).

The table 1 shows that the fuzzy availability of the system decreases approximately by 0.00027875 to 0.001705193 with the increase in failure rate from 0.001 to 0.004 (with increment of 0.001 ) for different values of system coverage factor and repair rates. Also fuzzy availability of system increases approximately by 0.000014142 to 0.001127752 with the increase in repair rates from 0.5 to 0.8 (with increment of 0.1 ) and increase of coverage factor with an increment of 0.1 .

\section{(ii) Effect of failure rates and repair rates of Forming on fuzzy availability of the}

System: - Effect of failure and repair rates of sub-system, namely, forming on fuzzy availability of the system is studied by varying the values of $\lambda_{2} \& \mu_{2}$. The failure and repair rates of other sub-systems have been taken as: $\lambda_{1}$ $=0.005, \lambda_{3}=0.004, \lambda_{4}=0.0015, \lambda_{5}=0.0052, \lambda_{6}=0.0002, \lambda_{7}=0.0001, \lambda_{8}=0.008, \lambda_{9}=0.0047, \mu_{1}=0.05, \mu_{3}=0.46, \mu_{4}$ $=0.1, \mu_{5}=0.08, \mu_{6}=0.009, \mu_{7}=0.002, \mu_{8}=0.31, \mu_{9}=0.5$. The fuzzy availability of the system is calculated using this data and the results are shown in Table 2(given in appendix-A).

The table 2 shows that the fuzzy availability of the system decreases approximately by 0.000008838 to 0.000062588 with the increase in failure rate from 0.0002 to 0.0005 (with increment of 0.0001 ) for different values of system coverage factor and repair rates. Also fuzzy availability of system increases approximately by 0.000004419 to 0.000018297 with the 
increase in repair rates from 0.02 to 0.05 (with increment of 0.01 ) and increase of coverage factor with an increment of 0.1 .

(iii) Effect of failure rates and repair rates of Moulder and Cutter on fuzzy availability of the System: - Here, the effect of failure and repair rates of sub-system moulder and cutter on fuzzy availability of the system is studied by varying their values as: $\lambda_{3}=0.005,0.006,0.007$ and $0.008 \& \mu_{3}=0.47,0.48,0.49$ and 0.50 . The failure and repair rates of other sub-systems have been taken as: $\lambda_{1}=0.006, \lambda_{2}=0.0001, \lambda_{4}=0.0015, \lambda_{5}=0.0052$, $\lambda_{6}=0.0002, \lambda_{7}=0.0001, \lambda_{8}=0.008, \lambda_{9}=0.0047, \mu_{1}=0.5, \mu_{2}=0.01, \mu_{4}=0.1, \mu_{5}=0.08, \mu_{6}=0.009, \mu_{7}=0.002, \mu_{8}=0.31$, $\mu_{9}=0.5$.

The table 3 (given in appendix-A) shows that the fuzzy availability of the system decreases approximately by 0.000129569 to 0.002404845 with the increase in failure rate from 0.005 to 0.008 (with increment of 0.001 ) for different values of system coverage factor and repair rates. Also fuzzy availability of system increases approximately by 0.000007464 to 0.000024946 with the increase in repair rates from 0.47 to 0.50 (with increment of 0.01 ) and increase of coverage factor with an increment of 0.1 .

\section{(iv) Effect of failure rates and repair rates of Baking Oven on fuzzy availability of the}

System: - Here, we have varied the failure and repair rates of baking oven as: $\lambda_{4}=0.0016,0.0017,0.0018,0.0019$ and $\mu_{4}=0.2,0.3,0.4,0.5$. Other failure and repair rates of the sub-systems have been taken as: $\lambda_{1}=0.005, \lambda_{2}=0.0001$, $\lambda_{3}=0.008, \lambda_{5}=0.0052, \lambda_{6}=0.0002, \lambda_{7}=0.0001, \lambda_{8}=0.008, \lambda_{9}=0.0047, \mu_{1}=0.5, \mu_{2}=0.01, \mu_{3}=0.52, \mu_{5}=0.08, \mu_{6}$ $=0.009, \mu_{7}=0.002, \mu_{8}=0.31, \mu_{9}=0.5$.

The table 4 (given in appendix-A) shows that the fuzzy availability of the system decreases approximately by 0.000019216 to 0.000388274 with the increase in failure rate from 0.0016 to 0.0019 (with increment of 0.0001 ) for different values of system coverage factor and repair rates. Also fuzzy availability of system increases approximately by 0.000076866 to 0.002700307 with the increase in repair rates from 0.2 to 0.5 (with increment of 0.1 ) and increase of coverage factor with an increment of 0.1 .

(v) Effect of failure rates and repair rates of Cooling Conveyor on fuzzy availability of the System: - We have also calculated the fuzzy availability of the system after varying the failure and repair rates of cooling conveyor sub-system. Following data has been used and results are shown in Table 5 (given in appendix-A). Four levels each of failure and repair rates of this sub-system have been considered as: $\lambda_{5}=0.0053,0.0054,0.0055$, 0.0056 and $\mu_{5}=0.06,0.07,0.08,0.9$. These rates for other sub-systems have been taken as: $\lambda_{1}=0.007, \lambda_{2}=0.0001, \lambda_{3}$ $=0.008, \lambda_{4}=0.0014, \lambda_{6}=0.0002, \lambda_{7}=0.0001, \lambda_{8}=0.008, \lambda_{9}=0.0047, \mu_{1}=0.5, \mu_{2}=0.01, \mu_{3}=0.52, \mu_{4}=0.6, \mu_{6}=0.009, \mu_{7}$ $=0.002, \mu_{3}=0.31, \mu_{9}=0.7$.

The table 5 shows that the fuzzy availability of the system decreases approximately by 0.000107294 to 0.001363717 with the increase in failure rate from 0.0053 to 0.0056 (with increment of 0.0001 ) for different values of system coverage factor and repair rates. Also fuzzy availability of system increases approximately by 0.004585538 to 0.01046051 with the increase in repair rates from 0.06 to 0.09 (with increment of 0.01 ) and increase of coverage factor with an increment of 0.1 .

\section{(vi) Effect of failure rates and repair rates of Packing on fuzzy availability of the}

System: - The effect of fuzzy availability on the system is studied by varying the values of $\lambda_{6} \& \mu_{6}$. The failure and repair rates of other sub-systems have been taken as: $\lambda_{1}=0.007, \lambda_{2}=0.0001, \lambda_{3}=0.008, \lambda_{4}=0.0014, \lambda_{5}=0.0057, \lambda_{7}$ $=0.0001, \lambda_{8}=0.008, \lambda_{9}=0.0047, \mu_{1=0.5}, \mu_{2}=0.01, \mu_{3}=0.52, \mu_{4}=0.6, \mu_{5}=0.09, \mu_{7}=0.002, \mu_{8}=0.31, \mu_{9=0.9}$.

The table 6 (given in appendix-A) shows that the fuzzy availability of the system decreases approximately by 0.000055922 to 0.000967576 with the increase in failure rate from 0.0006 to 0.0009 (with increment of 0.0001 ) for different values of system coverage factor and repair rates. Also fuzzy availability of system increases approximately by 0.000058106 to 0.000780625 with the increase in repair rates from 0.06 to 0.09 (with increment of 0.01 ) and increase of coverage factor with an increment of 0.1 .

\section{CONCLUSION}

Detailed study of Table 1 to Table 6 reveals that failure rates of mixing sub-system \& repair rates of baking oven subsystem (also shown in figure 2 and figure 3 which are given in appendix-1) has maximum effect on fuzzy availability of the complete system. Other sub-systems are almost equally effective. Thus, we can make an inference that we should take the most care of these sub-systems in order to improve the overall fuzzy availability of the system. 


\section{REFERENCES}

[1] Aliev I. M., Kara Z. 2004. Fuzzy system reliability analysis using time dependent fuzzy set. Control and Cybernetics 33(4), 653-662.

[2] Cai K. Y. 1996. Introduction to Fuzzy Reliability. Kluwer Academic Publishers, Norwell, MA, USA, ISBN: 0792397371.

[3] Cai K. Y. and Wen C. Y. 1990. Street-Lighting lamps replacement: A fuzzy viewpoint. Fuzzy Sets and Systems 37, 161-172.

[4] Cai K. Y., Wen C. Y. and Zhang M. L. 1991. Fuzzy reliability modeling of gracefully degradable computing systems. Reliability Engineering and System Safety 33,141-157.

[5] Cai K. Y., Wen C. Y. and Zhang M. L. 1991A. Survivability index for CCNs: A measure of fuzzy reliability . Reliability Engineering and System Safety 33, 71-99.

[6] Cai K. Y., Wen C. Y. and Zhang M. L. 1993. Fuzzy states as a basis for a theory of fuzzy reliability, Microelectronics Reliability 33, 2253-2263.

[7] Cai K. Y., Wen C. Y. and Zhang M. L. 1995. Mixture models in profust reliability theory. Microelectronics Reliability 35, 985-993.

[8] Chen S. M. 1996. New method for fuzzy system reliability analysis. Cybernetics and Systems: An International Journal 27(4), 385-401.

[9] Chongshan G. 2009. Fuzzy availability analysis of a repairable consecutive-2-out-of-3: F System. IEEE International Conference on Grey Systems and Intelligent Services, Nov. 10-12, 434-437.

[10] Chowdhury S. G. and Misra K. B. 1992. Evaluation of fuzzy reliability of a Non-series parallel network. Microelectronics Reliability 32, 1-4.

[11] Guan J. and Wu Y. 2006. Repairable consecutive-k-out-of-n: F system with fuzzy states. Fuzzy Sets and Systems 157, 121-142.

[12] Kumar K., Singh J. and Kumar P. 2009. Fuzzy reliability and fuzzy availability of the serial process in butter-oil processing plant. Journal of Mathematics and Statistics

(Science Publication, USA) 5(1), 65-71.

[13] Mohanta D. K., Sadhu P. K. and Chakrabarti R. 2005. Fuzzy Markov Model for Determination of Fuzzy State Probabilities of Generating Units Including the Effect of Maintenance Scheduling. IEEE Transactions on Power Systems 20(4), 2117-2124.

[14] Pandey D. and Tyagi S. K. 2007. Profust reliability of a gracefully degradable system; Fuzzy Sets and System 158, 794-803.

[15] Qiang Xu, Jing Li and Chen J. Y. 2009. Fuzzy Reliability Analysis of Deep Sliding Plane in Rock Foundation under Dam. IEEE Sixth International Conference on Fuzzy Systems and Knowledge Discovery , 525-529.

[16] Verma A. K. et al 2007. Fuzzy-Reliability Engineering: Concepts and Applications. 1st Edition, Narosa Publishing House, UK, ISBN: 9788173196690.

[17] Zadeh L. A. 1965. Fuzzy Sets. Information and Control 8, 338-53.

[18] Zuang H. Z. 1995. Reliability analysis method in the presence of fuzziness attached to operating time. Microelectronics Reliability 35, 1483-1487. 


\section{APPENDIX-1}

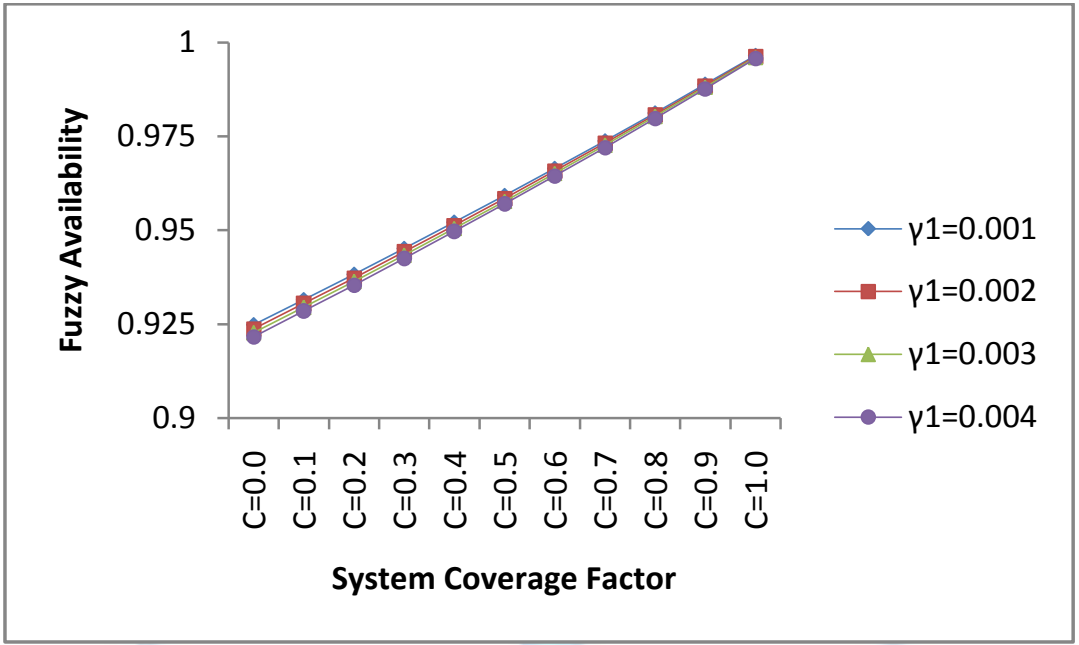

Fig. 2 Effect of failure rates of mixing subsystem on fuzzy availability for different values of system coverage factor

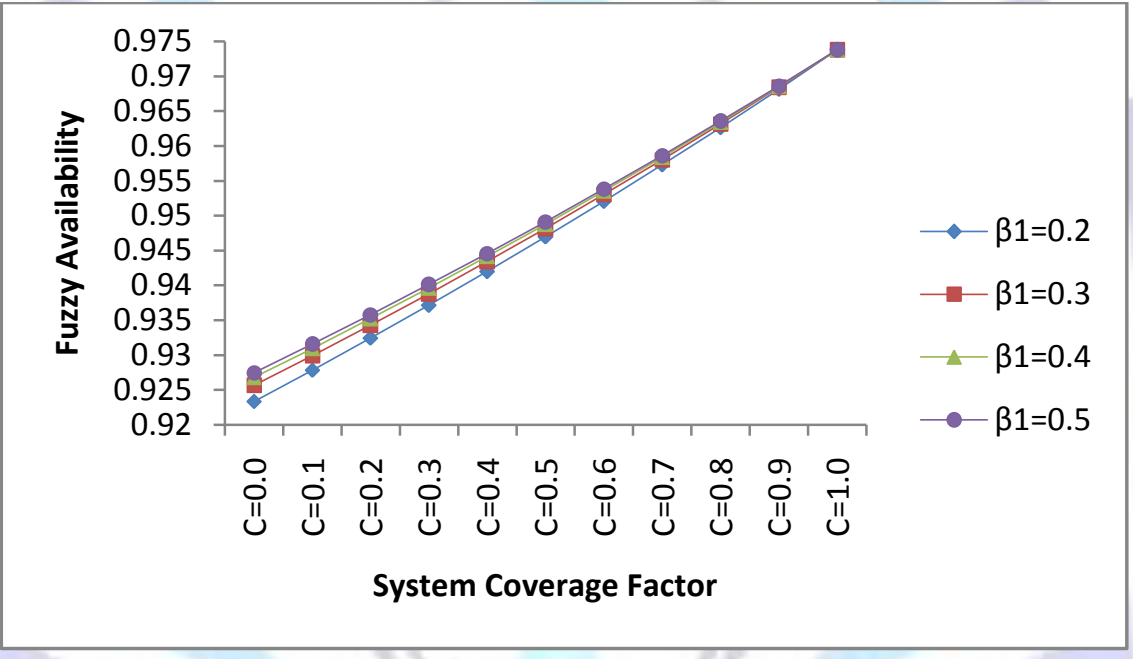

Fig. 3 Effect of repair rates of baking oven subsystem on fuzzy availability for different values of system coverage factor

\section{APPENDIX-A}

Table 1: Effect of failure rates and repair rates of mixing on fuzzy availability

\begin{tabular}{|l|l|l|l|l|l|}
\hline $\begin{array}{l}\text { System } \\
\text { Coverage } \\
\text { Factor }\end{array}$ & $\mu_{1}$ & $\lambda_{1} \rightarrow 0.001$ & 0.002 & 0.003 & 0.004 \\
\hline $\mathrm{C}=0.0$ & 0.5 & 0.924214418 & 0.922509225 & 0.920810313 & 0.919117647 \\
& 0.6 & 0.924499230 & 0.923076923 & 0.921658986 & 0.920245399 \\
& 0.7 & 0.924702774 & 0.923482850 & 0.922266140 & 0.921052632 \\
& 0.8 & 0.924855491 & 0.923787529 & 0.922722030 & 0.921658986 \\
\hline $\mathrm{C}=0.1$ & 0.5 & 0.930921693 & 0.929303735 & 0.927691934 & 0.926086256 \\
& 0.6 & 0.931183139 & 0.929832177 & 0.928485522 & 0.927143154 \\
& 0.7 & 0.931369988 & 0.930210038 & 0.929053275 & 0.927899686 \\
& 0.8 & 0.931510181 & 0.930493654 & 0.929479585 & 0.928467966 \\
\hline $\mathrm{C}=0.2$ & 0.5 & 0.937737925 & 0.936214538 & 0.934697157 & 0.933185745 \\
& 0.6 & & & & \\
\hline
\end{tabular}




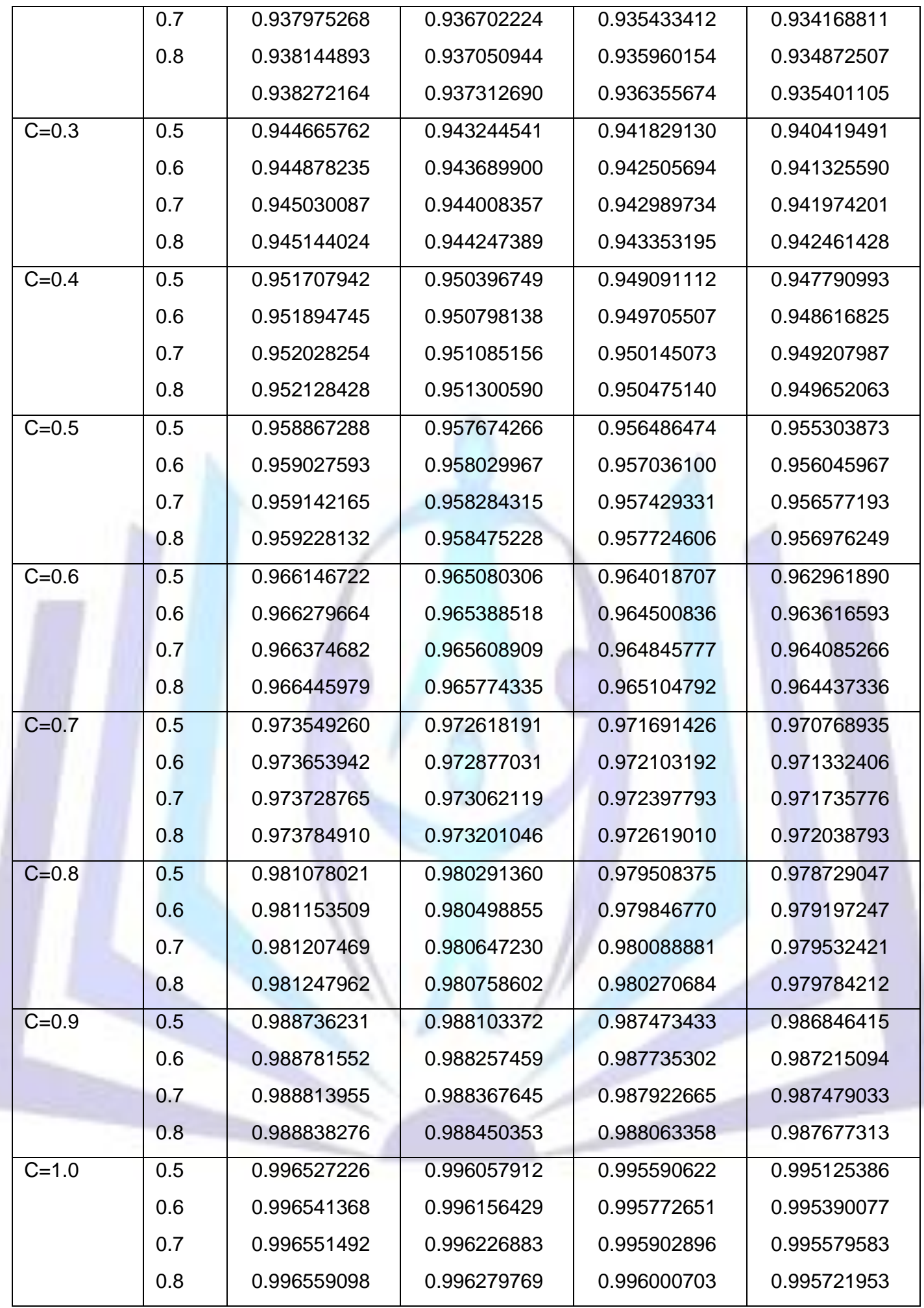

Table 2: Effect of failure rates and repair rates of forming on fuzzy availability

\begin{tabular}{|l|l|l|l|l|l|}
\hline $\begin{array}{l}\text { System } \\
\text { Coverage } \\
\text { Factor }\end{array}$ & $\mu_{2}$ & $\lambda_{2} \rightarrow 0.0002$ & 0.0003 & 0.0004 & 0.0005 \\
\hline $\mathrm{C}=0.0$ & 0.02 & 0.917431193 & 0.917431193 & 0.917431193 & 0.917431193 \\
& 0.03 & 0.917431193 & 0.917431193 & 0.917431193 & 0.917431193 \\
& 0.04 & 0.917431193 & 0.917431193 & 0.917431193 & 0.917431193 \\
\hline
\end{tabular}




\begin{tabular}{|c|c|c|c|c|c|}
\hline & 0.05 & 0.917431193 & 0.917431193 & 0.917431193 & 0.917431193 \\
\hline \multirow[t]{4}{*}{$\mathrm{C}=0.1$} & 0.02 & 0.922861911 & 0.922837382 & 0.922812853 & 0.922788326 \\
\hline & 0.03 & 0.922878265 & 0.922861911 & 0.922845558 & 0.922829205 \\
\hline & 0.04 & 0.922886442 & 0.922874177 & 0.922861911 & 0.922849646 \\
\hline & 0.05 & 0.922891349 & 0.922881536 & 0.922871724 & 0.922861911 \\
\hline \multirow[t]{4}{*}{$\mathrm{C}=0.2$} & 0.02 & 0.928548094 & 0.928505154 & 0.928462218 & 0.928419286 \\
\hline & 0.03 & 0.928576723 & 0.928548094 & 0.928519467 & 0.928490842 \\
\hline & 0.04 & 0.928591038 & 0.928569566 & 0.928548094 & 0.928526624 \\
\hline & 0.05 & 0.928599627 & 0.928582449 & 0.928565271 & 0.928548094 \\
\hline \multirow[t]{4}{*}{$\mathrm{C}=0.3$} & 0.02 & 0.934486041 & 0.934430505 & 0.934374975 & 0.934319453 \\
\hline & 0.03 & 0.934523068 & 0.934486041 & 0.934449016 & 0.934411994 \\
\hline & 0.04 & 0.934541583 & 0.934513811 & 0.934486041 & 0.934458272 \\
\hline & 0.05 & 0.934552692 & 0.934530474 & 0.934508257 & 0.934486041 \\
\hline \multirow[t]{4}{*}{$\mathrm{C}=0.4$} & 0.02 & 0.940672842 & 0.940610254 & 0.940547676 & 0.940485105 \\
\hline & 0.03 & 0.940714571 & 0.940672842 & 0.940631116 & 0.940589394 \\
\hline & 0.04 & 0.940735437 & 0.940704138 & 0.940672842 & 0.940641547 \\
\hline & 0.05 & 0.940747957 & 0.940722917 & 0.940697879 & 0.940672842 \\
\hline \multirow[t]{4}{*}{$\mathrm{C}=0.5$} & 0.02 & 0.947106313 & 0.947041981 & 0.946977658 & 0.946913344 \\
\hline & 0.03 & 0.947149206 & 0.947106313 & 0.947063424 & 0.947020539 \\
\hline & 0.04 & 0.947170654 & 0.947138482 & 0.947106313 & 0.947074146 \\
\hline & 0.05 & 0.947183523 & 0.947157785 & 0.947132048 & 0.947106313 \\
\hline \multirow[t]{4}{*}{$\mathrm{C}=0.6$} & 0.02 & 0.953784943 & 0.953723963 & 0.953662990 & 0.953602025 \\
\hline & 0.03 & 0.953825601 & 0.953784943 & 0.953744288 & 0.953703637 \\
\hline & 0.04 & 0.953845931 & 0.953815436 & 0.953784943 & 0.953754452 \\
\hline & 0.05 & 0.953858130 & 0.953833733 & 0.953809337 & 0.953784943 \\
\hline \multirow[t]{4}{*}{$\mathrm{C}=0.7$} & 0.02 & 0.960707842 & 0.960655124 & 0.960602412 & 0.960549705 \\
\hline & 0.03 & 0.960742991 & 0.960707842 & 0.960672696 & 0.960637553 \\
\hline & 0.04 & 0.960760566 & 0.960734203 & 0.960707842 & 0.960681482 \\
\hline & 0.05 & 0.960771112 & 0.960750021 & 0.960728931 & 0.960707842 \\
\hline \multirow[t]{4}{*}{$\mathrm{C}=0.8$} & 0.02 & 0.967874706 & 0.967834997 & 0.967795292 & 0.967755590 \\
\hline & 0.03 & 0.967901180 & 0.967874706 & 0.967848233 & 0.967821762 \\
\hline & 0.04 & 0.967914417 & 0.967894561 & 0.967874706 & 0.967854851 \\
\hline & 0.05 & 0.967922360 & 0.967906475 & 0.967890590 & 0.967874706 \\
\hline \multirow[t]{4}{*}{$\mathrm{C}=0.9$} & 0.02 & 0.975285777 & 0.975263683 & 0.975241590 & 0.975219498 \\
\hline & 0.03 & 0.975300507 & 0.975285777 & 0.975271048 & 0.975256319 \\
\hline & 0.04 & 0.975307872 & 0.975296825 & 0.975285777 & 0.975274730 \\
\hline & 0.05 & 0.975312291 & 0.975303453 & 0.975294615 & 0.975285777 \\
\hline \multirow[t]{4}{*}{$\mathrm{C}=1.0$} & 0.02 & 0.98294182 & 0.98294182 & 0.98294182 & 0.98294182 \\
\hline & 0.03 & 0.98294182 & 0.98294182 & 0.98294182 & 0.98294182 \\
\hline & 0.04 & 0.98294182 & 0.98294182 & 0.98294182 & 0.98294182 \\
\hline & 0.05 & 0.98294182 & 0.98294182 & 0.98294182 & 0.98294182 \\
\hline
\end{tabular}


Table 3: Effect of failure rates and repair rates of moulder and cutter on fuzzy availability

\begin{tabular}{|c|c|c|c|c|c|}
\hline $\begin{array}{l}\text { System } \\
\text { Coverage } \\
\text { Factor }\end{array}$ & $\mu_{3}$ & $\lambda_{3} \rightarrow 0.005$ & 0.006 & 0.007 & 0.008 \\
\hline \multirow[t]{4}{*}{$\mathrm{C}=0.0$} & 0.47 & 0.915750916 & 0.915750916 & 0.915750916 & 0.915750916 \\
\hline & 0.48 & 0.915750916 & 0.915750916 & 0.915750916 & 0.915750916 \\
\hline & 0.49 & 0.915750916 & 0.915750916 & 0.915750916 & 0.915750916 \\
\hline & 0.50 & 0.915750916 & 0.915750916 & 0.915750916 & 0.915750916 \\
\hline \multirow[t]{4}{*}{$\mathrm{C}=0.1$} & 0.47 & 0.921117547 & 0.920982848 & 0.920845816 & 0.920706376 \\
\hline & 0.48 & 0.921123716 & 0.920990790 & 0.920855568 & 0.920717974 \\
\hline & 0.49 & 0.921129705 & 0.920998488 & 0.920865010 & 0.920729197 \\
\hline & 0.50 & 0.921135521 & 0.921005952 & 0.920874156 & 0.920740059 \\
\hline \multirow[t]{4}{*}{$\mathrm{C}=0.2$} & 0.47 & 0.926778735 & 0.926491577 & 0.926194296 & 0.925886227 \\
\hline & 0.48 & 0.926789125 & 0.926505199 & 0.926211280 & 0.925906710 \\
\hline & 0.49 & 0.926799223 & 0.926518412 & 0.926227734 & 0.925926540 \\
\hline & 0.50 & 0.926809037 & 0.926531230 & 0.926243680 & 0.925945741 \\
\hline \multirow[t]{4}{*}{$\mathrm{C}=0.3$} & 0.47 & 0.932728700 & 0.932276181 & 0.931799389 & 0.931295890 \\
\hline & 0.48 & 0.932741492 & 0.932293302 & 0.931821098 & 0.931322470 \\
\hline & 0.49 & 0.932753941 & 0.932309925 & 0.931842146 & 0.931348216 \\
\hline & 0.50 & 0.932766054 & 0.932326066 & 0.931862557 & 0.931373162 \\
\hline \multirow[t]{4}{*}{$\mathrm{C}=0.4$} & 0.47 & 0.938962760 & 0.938336329 & 0.937664559 & 0.936941288 \\
\hline & 0.48 & 0.938976243 & 0.938354837 & 0.937688489 & 0.936971084 \\
\hline & 0.49 & 0.938989389 & 0.938372833 & 0.937711715 & 0.936999969 \\
\hline & 0.50 & 0.939002207 & 0.938390330 & 0.937734262 & 0.937027980 \\
\hline \multirow[t]{4}{*}{$\mathrm{C}=0.5$} & 0.47 & 0.945477220 & 0.944672250 & 0.943793708 & 0.942828881 \\
\hline & 0.48 & 0.945489777 & 0.944690094 & 0.943817348 & 0.942858902 \\
\hline & 0.49 & 0.945502062 & 0.944707482 & 0.943840331 & 0.942888045 \\
\hline & 0.50 & 0.945514077 & 0.944724424 & 0.943862676 & 0.942916341 \\
\hline \multirow[t]{4}{*}{$\mathrm{C}=0.6$} & 0.47 & 0.952269289 & 0.951284714 & 0.950191185 & 0.948965708 \\
\hline & 0.48 & 0.952279387 & 0.951299890 & 0.950212006 & 0.948992839 \\
\hline & 0.49 & 0.952289331 & 0.951314738 & 0.950232307 & 0.949019237 \\
\hline & 0.50 & 0.952299113 & 0.951329259 & 0.950252098 & 0.949044921 \\
\hline \multirow[t]{4}{*}{$\mathrm{C}=0.7$} & 0.47 & 0.959337009 & 0.958175006 & 0.956861792 & 0.955359438 \\
\hline & 0.48 & 0.959343186 & 0.958185551 & 0.956877237 & 0.955380417 \\
\hline & 0.49 & 0.959349377 & 0.958195965 & 0.956892391 & 0.955400927 \\
\hline & 0.50 & 0.959355566 & 0.958206239 & 0.956907252 & 0.955420970 \\
\hline \multirow[t]{4}{*}{$\mathrm{C}=0.8$} & 0.47 & 0.966679186 & 0.965344915 & 0.963810796 & 0.962018431 \\
\hline & 0.48 & 0.966680040 & 0.965348895 & 0.963818270 & 0.962029826 \\
\hline & 0.49 & 0.966681129 & 0.965353014 & 0.963825778 & 0.962041142 \\
\hline & 0.50 & 0.966682421 & 0.965357245 & 0.963833299 & 0.962052360 \\
\hline
\end{tabular}




\begin{tabular}{|l|l|l|l|l|l|}
\hline $\mathrm{C}=0.9$ & 0.47 & 0.974279356 & 0.972784621 & 0.971035846 & 0.968947643 \\
& 0.48 & 0.974284212 & 0.972788205 & 0.971038119 & 0.968948615 \\
& 0.49 & 0.974289525 & 0.972792221 & 0.971040802 & 0.968949982 \\
& 0.50 & 0.974295341 & 0.972796715 & 0.971043942 & 0.968951795 \\
\hline $\mathrm{C}=1.0$ & 0.47 & 0.982146693 & 0.980491167 & 0.978520965 & 0.976116120 \\
& 0.48 & 0.982158907 & 0.980504322 & 0.978535537 & 0.976132847 \\
& 0.49 & 0.982171875 & 0.980518295 & 0.978551013 & 0.976150602 \\
& 0.50 & 0.982185661 & 0.980533155 & 0.978567471 & 0.976169471 \\
\hline
\end{tabular}

Table 4: Effect of failure rates and repair rates of baking oven on fuzzy availability

\begin{tabular}{|c|c|c|c|c|c|}
\hline $\begin{array}{l}\text { System } \\
\text { Coverage } \\
\text { Factor }\end{array}$ & $\mu_{4}$ & $\lambda_{4} \rightarrow 0.0016$ & 0.0017 & 0.0018 & 0.0019 \\
\hline \multirow[t]{4}{*}{$\mathrm{C}=0.0$} & 0.2 & 0.923361034 & 0.922934933 & 0.922509225 & 0.922083910 \\
\hline & 0.3 & 0.925640234 & 0.925354719 & 0.925069380 & 0.924784217 \\
\hline & 0.4 & 0.926784059 & 0.926569377 & 0.926354794 & 0.926140310 \\
\hline & 0.5 & 0.927471712 & 0.927299703 & 0.927127758 & 0.926955877 \\
\hline \multirow[t]{4}{*}{$\mathrm{C}=0.1$} & 0.2 & 0.927826681 & 0.927438407 & 0.927050458 & 0.926662834 \\
\hline & 0.3 & 0.929902977 & 0.929642932 & 0.929383032 & 0.929123278 \\
\hline & 0.4 & 0.930944614 & 0.930749129 & 0.930553727 & 0.930358406 \\
\hline & 0.5 & 0.931570717 & 0.931414112 & 0.931257560 & 0.931101061 \\
\hline \multirow[t]{4}{*}{$\mathrm{C}=0.2$} & 0.2 & 0.932415344 & 0.932065836 & 0.931716590 & 0.931367606 \\
\hline & 0.3 & 0.934283823 & 0.934049854 & 0.933816002 & 0.933582267 \\
\hline & 0.4 & 0.935220874 & 0.935045034 & 0.934869260 & 0.934693552 \\
\hline & 0.5 & 0.935784007 & 0.935643160 & 0.935502356 & 0.935361594 \\
\hline \multirow[t]{4}{*}{$\mathrm{C}=0.3$} & 0.2 & 0.937128779 & 0.936819018 & 0.936509462 & 0.936200110 \\
\hline & 0.3 & 0.938784303 & 0.938577042 & 0.938369874 & 0.938162796 \\
\hline & 0.4 & 0.939614260 & 0.939458531 & 0.939302854 & 0.939147229 \\
\hline & 0.5 & 0.940112939 & 0.939988220 & 0.939863533 & 0.939738880 \\
\hline \multirow[t]{4}{*}{$\mathrm{C}=0.4$} & 0.2 & 0.941968736 & 0.941699749 & 0.941430915 & 0.941162235 \\
\hline & 0.3 & 0.943405932 & 0.943226043 & 0.943046222 & 0.942866470 \\
\hline & 0.4 & 0.944126176 & 0.943991047 & 0.943855956 & 0.943720904 \\
\hline & 0.5 & 0.944558851 & 0.944450645 & 0.944342464 & 0.944234308 \\
\hline \multirow[t]{4}{*}{$\mathrm{C}=0.5$} & 0.2 & 0.946936946 & 0.946709807 & 0.946482777 & 0.946255855 \\
\hline & 0.3 & 0.948150199 & 0.947998373 & 0.947846595 & 0.947694865 \\
\hline & 0.4 & 0.948757993 & 0.948643972 & 0.948529979 & 0.948416013 \\
\hline & 0.5 & 0.949123043 & 0.949031754 & 0.948940482 & 0.948849229 \\
\hline \multirow[t]{4}{*}{$\mathrm{C}=0.6$} & 0.2 & 0.952035103 & 0.951850934 & 0.951666837 & 0.951482810 \\
\hline & 0.3 & 0.953018542 & 0.952895501 & 0.952772492 & 0.952649515 \\
\hline & 0.4 & 0.953511024 & 0.953418645 & 0.953326284 & 0.953233941 \\
\hline & 0.5 & 0.953806758 & 0.953732807 & 0.9536588688 & 0.953584941 \\
\hline \multirow[t]{2}{*}{$\mathrm{C}=0.7$} & 0.2 & 0.957264833 & 0.957124809 & 0.956984825 & 0.956844883 \\
\hline & 0.3 & 0.958012323 & 0.957918823 & 0.957825341 & 0.957731877 \\
\hline
\end{tabular}




\begin{tabular}{|l|l|l|l|l|l|}
\hline & 0.4 & 0.958386506 & 0.958316324 & 0.958246153 & 0.958175992 \\
& 0.5 & 0.958611156 & 0.958554983 & 0.958498817 & 0.958442658 \\
\hline $\mathrm{C}=0.8$ & 0.2 & 0.962627666 & 0.962533013 & 0.962438380 & 0.962343764 \\
& 0.3 & 0.963132793 & 0.963069623 & 0.963006462 & 0.962943308 \\
& 0.4 & 0.963385556 & 0.963338153 & 0.963290754 & 0.963243361 \\
& 0.5 & 0.963537277 & 0.963499342 & 0.963461411 & 0.963423482 \\
\hline $\mathrm{C}=0.9$ & 0.2 & 0.968124991 & 0.968076994 & 0.968029002 & 0.967981014 \\
& 0.3 & 0.968381056 & 0.968349040 & 0.968317027 & 0.968285016 \\
& 0.4 & 0.968509139 & 0.968485121 & 0.968461104 & 0.968437088 \\
& 0.5 & 0.968586005 & 0.968566787 & 0.968547570 & 0.968528354 \\
\hline $\mathrm{C}=1.0$ & 0.2 & 0.973758009 & 0.973758009 & 0.973758009 & 0.973758009 \\
& 0.3 & 0.973758009 & 0.973758009 & 0.973758009 & 0.973758009 \\
& 0.4 & 0.973758009 & 0.973758009 & 0.973758009 & 0.973758009 \\
& 0.5 & 0.973758009 & 0.973758009 & 0.973758009 & 0.973758009 \\
\hline
\end{tabular}

Table 5: Effect of failure rates and repair rates of cooling conveyor on fuzzy availability

\begin{tabular}{|c|c|c|c|c|c|}
\hline $\begin{array}{l}\text { System } \\
\text { Coverage } \\
\text { Factor }\end{array}$ & $\mu_{5}$ & $\lambda_{5} \rightarrow 0.0053$ & 0.0054 & 0.0055 & 0.0056 \\
\hline \multirow[t]{4}{*}{$\mathrm{C}=0.0$} & 0.06 & 0.90525043 & 0.903886713 & 0.902527076 & 0.901171523 \\
\hline & 0.07 & 0.91571094 & 0.914514654 & 0.913321446 & 0.912131347 \\
\hline & 0.08 & 0.92371649 & 0.922651084 & 0.921588204 & 0.920527769 \\
\hline & 0.09 & 0.93004032 & 0.929080211 & 0.928122100 & 0.927165963 \\
\hline \multirow[t]{4}{*}{$\mathrm{C}=0.1$} & 0.06 & 0.911060515 & 0.909813199 & 0.908569293 & 0.907328783 \\
\hline & 0.07 & 0.920614556 & 0.919522651 & 0.918433332 & 0.917346591 \\
\hline & 0.08 & 0.927912630 & 0.926941837 & 0.925973072 & 0.925006330 \\
\hline & 0.09 & 0.933669402 & 0.932795609 & 0.931923449 & 0.931052919 \\
\hline \multirow[t]{4}{*}{$\mathrm{C}=0.2$} & 0.06 & 0.917175516 & 0.916048320 & 0.914923890 & 0.913802216 \\
\hline & 0.070 & 0.925797335 & 0.924812692 & 0.923830139 & 0.922849672 \\
\hline & .08 & 0.932370832 & 0.931496824 & 0.930624453 & 0.929753714 \\
\hline & 0.09 & 0.937548446 & 0.936762771 & 0.935978410 & 0.935195361 \\
\hline \multirow[t]{4}{*}{$\mathrm{C}=0.3$} & 0.06 & 0.923600054 & 0.922596926 & 0.921595973 & 0.920597189 \\
\hline & 0.07 & 0.931262094 & 0.930387737 & 0.929515019 & 0.928643936 \\
\hline & 0.08 & 0.937092573 & 0.936317744 & 0.935544193 & 0.934771919 \\
\hline & 0.09 & 0.941678111 & 0.940982493 & 0.940287900 & 0.939594331 \\
\hline \multirow[t]{4}{*}{$\mathrm{C}=0.4$} & 0.06 & 0.930339387 & 0.929464539 & 0.928591333 & 0.927719766 \\
\hline & 0.07 & 0.937012185 & 0.936251334 & 0.935491717 & 0.934733331 \\
\hline & 0.08 & 0.942079940 & 0.941406832 & 0.940734684 & 0.940063495 \\
\hline & 0.09 & 0.946059585 & 0.945456085 & 0.944853355 & 0.944251391 \\
\hline \multirow[t]{4}{*}{$\mathrm{C}=0.5$} & 0.06 & 0.937399441 & 0.936657363 & 0.935916458 & 0.935176724 \\
\hline & 0.07 & 0.943051542 & 0.942407624 & 0.941764584 & 0.941122420 \\
\hline & 0.08 & 0.947335551 & 0.9467668667 & 0.9461988665 & 0.945631544 \\
\hline & 0.09 & 0.950694563 & 0.950185372 & 0.949676726 & 0.949168624 \\
\hline
\end{tabular}




\begin{tabular}{|l|l|l|l|l|l|}
\hline $\mathrm{C}=0.6$ & 0.06 & 0.944786830 & 0.944182306 & 0.943578555 & 0.942975575 \\
& 0.07 & 0.949384695 & 0.948861348 & 0.948338578 & 0.947816383 \\
& 0.08 & 0.952862570 & 0.952401178 & 0.951940231 & 0.951479730 \\
& 0.09 & 0.955585251 & 0.955172691 & 0.954760487 & 0.954348638 \\
\hline $\mathrm{C}=0.7$ & 0.06 & 0.952508876 & 0.952047000 & 0.951585572 & 0.951124590 \\
& 0.07 & 0.956016776 & 0.955617866 & 0.955219287 & 0.954821041 \\
& 0.08 & 0.958664705 & 0.958313643 & 0.957962838 & 0.957612289 \\
& 0.09 & 0.960734367 & 0.960420897 & 0.960107631 & 0.959794569 \\
\hline $\mathrm{C}=0.8$ & 0.06 & 0.960573635 & 0.960259828 & 0.959946226 & 0.959632828 \\
& 0.07 & 0.962953541 & 0.962683166 & 0.962412942 & 0.962142871 \\
& 0.08 & 0.964746224 & 0.964508711 & 0.964271315 & 0.964034036 \\
& 0.09 & 0.966145154 & 0.965933373 & 0.965721686 & 0.965510090 \\
\hline $\mathrm{C}=0.9$ & 0.06 & 0.968989926 & 0.968829955 & 0.968670037 & 0.968510171 \\
& 0.07 & 0.970201384 & 0.970063892 & 0.969926439 & 0.969789025 \\
& 0.08 & 0.971111966 & 0.970991409 & 0.970870881 & 0.970750384 \\
& 0.09 & 0.971821380 & 0.971714038 & 0.971606720 & 0.971499426 \\
\hline $\mathrm{C}=1.0$ & 0.06 & 0.977767362 & 0.977767362 & 0.977767362 & 0.977767362 \\
& 0.07 & 0.977767362 & 0.977767362 & 0.977767362 & 0.977767362 \\
& 0.08 & 0.977767362 & 0.977767362 & 0.977767362 & 0.977767362 \\
& 0.09 & 0.977767362 & 0.977767362 & 0.977767362 & 0.977767362 \\
\hline
\end{tabular}

Table 6: Effect of failure rates and repair rates of packing on fuzzy availability

\begin{tabular}{|l|l|l|l|l|l|}
\hline $\begin{array}{l}\text { System } \\
\text { Coverage } \\
\text { Factor }\end{array}$ & $\mu_{6}$ & \multicolumn{5}{|l}{$\lambda_{6} \rightarrow 0.0005$} & 0.0006 & 0.0008 \\
\hline $\mathrm{C}=0.0$ & 0.06 & 0.926211794 & 0.926211794 & 0.926211794 & 0.926211794 \\
& 0.07 & 0.926211794 & 0.926211794 & 0.926211794 & 0.926211794 \\
& 0.08 & 0.926211794 & 0.926211794 & 0.926211794 & 0.926211794 \\
& 0.09 & 0.926211794 & 0.926211794 & 0.926211794 & 0.926211794 \\
\hline $\mathrm{C}=0.1$ & 0.06 & 0.931952716 & 0.931857703 & 0.931762769 & 0.931667916 \\
& 0.07 & 0.932053820 & 0.931975631 & 0.931897497 & 0.931819418 \\
& 0.08 & 0.932129115 & 0.932063461 & 0.931997846 & 0.931932270 \\
& 0.09 & 0.932187221 & 0.932131241 & 0.932075291 & 0.932019369 \\
\hline $\mathrm{C}=0.2$ & 0.06 & 0.937817745 & 0.937627461 & 0.937437497 & 0.937247852 \\
& 0.07 & 0.938016496 & 0.937859718 & 0.937703160 & 0.937546822 \\
& 0.08 & 0.938164578 & 0.938032793 & 0.937901166 & 0.937769696 \\
& 0.09 & 0.938278900 & 0.938166424 & 0.938054065 & 0.937941823 \\
& 0.06 & 0.0943809622 & 0.943523761 & 0.943238620 & 0.942954197 \\
& 0.07 & 0.0 .944102596 & 0.943866795 & 0.943631489 & 0.943396677 \\
& 0.08 & 0.0944320976 & 0.944122558 & 0.943924497 & 0.943726789 \\
& 0.09 & 0.0944489635 & 0.944320126 & 0.944150880 & 0.943981896 \\
\hline $\mathrm{C}=0.4$ & 0.06 & 0.949931185 & 0.949549393 & 0.949168882 & 0.948789644 \\
& 0.07 & 0.950314993 & 0.949999698 & 0.949685286 & 0.949371752 \\
& & & &
\end{tabular}




\begin{tabular}{|l|l|l|l|l|l|}
\hline & 0.08 & 0.950601199 & 0.950335619 & 0.950070673 & 0.949806357 \\
& 0.09 & 0.950822327 & 0.950595224 & 0.950368589 & 0.950142423 \\
\hline $\mathrm{C}=0.5$ & 0.06 & 0.956185377 & 0.955707251 & 0.955231125 & 0.954756987 \\
& 0.07 & 0.956656659 & 0.956261365 & 0.955867452 & 0.955474912 \\
& 0.08 & 0.957008236 & 0.956674936 & 0.956342628 & 0.956011307 \\
& 0.09 & 0.957279972 & 0.956994691 & 0.956710146 & 0.956426334 \\
\hline $\mathrm{C}=0.6$ & 0.06 & 0.962575245 & 0.962000334 & 0.961428302 & 0.960859129 \\
& 0.07 & 0.963130670 & 0.962654836 & 0.962180992 & 0.961709127 \\
& 0.08 & 0.963545179 & 0.963143572 & 0.962743398 & 0.962344648 \\
& 0.09 & 0.963865669 & 0.963521605 & 0.963178603 & 0.962836660 \\
\hline $\mathrm{C}=0.7$ & 0.06 & 0.969103950 & 0.968431751 & 0.967763473 & 0.967099081 \\
& 0.07 & 0.969740215 & 0.969183260 & 0.96862902 & 0.968077474 \\
& 0.08 & 0.970215229 & 0.969744699 & 0.969276124 & 0.968809494 \\
& 0.09 & 0.970582627 & 0.970179146 & 0.969777119 & 0.969376539 \\
\hline $\mathrm{C}=0.8$ & 0.06 & 0.975774769 & 0.975004730 & 0.974239815 & 0.973479972 \\
& 0.07 & 0.976488591 & 0.975849900 & 0.975214760 & 0.974583143 \\
& 0.08 & 0.977021697 & 0.976481597 & 0.975944061 & 0.975409070 \\
& 0.09 & 0.977434163 & 0.976970610 & 0.976508964 & 0.976049214 \\
\hline $\mathrm{C}=0.9$ & 0.06 & 0.982591097 & 0.981722617 & 0.980860625 & 0.980005049 \\
& 0.07 & 0.983379219 & 0.982658136 & 0.981941557 & 0.981229441 \\
& 0.08 & 0.983968013 & 0.983357668 & 0.982750577 & 0.982146716 \\
& 0.09 & 0.984423712 & 0.983899405 & 0.983377522 & 0.982858048 \\
\hline & 0.06 & 0.989556460 & 0.988588884 & 0.987629325 & 0.986677684 \\
& 0.07 & 0.990415642 & 0.989611472 & 0.988812876 & 0.988019797 \\
& 0.08 & 0.991057730 & 0.990376431 & 0.989699164 & 0.989025895 \\
& 0.09 & 0.991554832 & 0.990969061 & 0.990386298 & 0.989806520 \\
\hline & & & & & \\
& & & \\
& & & \\
& & & \\
& & &
\end{tabular}

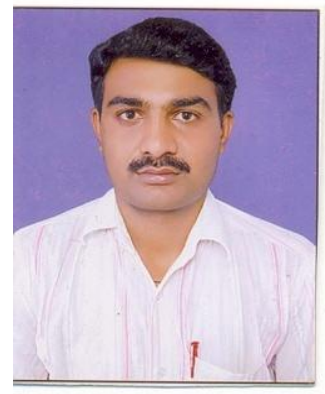

Pawan Kumar Chhoker is Senior Lecturer in the Department of Mathematics, N.C. College of Engineering, Israna (Panipat) (India). He did his MSC (Applied Mathematics) in 2005 from Kurukshetra University Kurukshetra. He completed his $\mathrm{PhD}$ in June 2013 from NIT Kurukshetra. Presently his area of interest is reliability theory. 